Original Research Paper

\title{
Understanding Hybrid Additive Manufacturing of Functional Devices
}

\author{
Santosh Kumar Parupelli and Salil Desai \\ Department of Industrial and Systems Engineering, North Carolina A\&T State University, Greensboro, USA
}

Article history

Received: 09-03-2017

Revised: 11-03-2017

Accepted: 20-03-2017

Corresponding Author:

Salil Desai

Department of Industrial and

Systems Engineering, North

Carolina A\&T State University,

Greensboro, USA

Email: sdesai@ncat.edu

\begin{abstract}
The fabrication of electronic components in three-dimensional space is critical for building multifunctional devices. Traditional manufacturing approaches are limited to building planar device configurations. In order to address this limitation, our group has developed a novel hybrid additive manufacturing process that can deposit multi-material patterns on conformal substrates. This direct-write approach involves the combination of microextrusion, pico jet and laser systems. A multi-axis robot was employed to deposit slurries and colloids of conductive materials on different substrates. Fine deposition of the slurries was achieved by tuning the process parameters such as deposition line speed, extrusion pressure, curing temperature, Z-height, laser beam spot, material type and laser intensity. Precise deposition of the medium viscous colloidal liquids was achieved by pico jet unit. Sintering of the micro/nano particles was achieved using a fiber optic laser system and micro wave furnace. The conductance of the deposited electrical trace varied based on the material type and trace cross-section area. This research lays the foundation to build a three-dimensional hierarchy of electronic components. By embedding components at various depths and orientations complex electronic circuitry with versatile material compositions and design flexibility can be fabricated in situ.
\end{abstract}

Keywords: 3D Printing, Hybrid Additive Manufacturing, Direct-Write Technique, Functional Electronics, In Situ Laser Curing

\section{Introduction}

Electronics have a ubiquitous impact across different areas such as healthcare, automobiles and manufacturing (Rashid, 2010). The miniaturization of electronic circuits has been one of the prominent achievements in the field of electronics (Palm et al., 2005). An Integrated Circuit (IC) is a package of electronic components that are arranged as arrays of passive and active components. The fabrication of an IC is a highly sophisticated process which requires clean rooms and specialized equipment such as photolithography, metallization and diffusion (Park et al., 2013). The passive components including capacitors, resistors and inductors are made of ceramic materials. Traditional manufacturing approaches consist of Printed Circuit Boards (PCB) in which the electronic components are interconnected using the conductive traces on an insulating substrate using etching processes (Gomes, 2012). Etching of PCB generates toxic chemicals that are hazardous to the environment (Lim and Schoenung, 2010). Reductions in the volume and weight of electronic devices can be obtained by embedding electronic components within geometrically complex three-Dimensional (3D) architectures at various depths (Espalin et al., 2014). Presently, there are a variety of techniques used by electronic manufacturers for the fabrication of multimaterial, multilayer ceramic components in complex architecture for advanced functionality of electronic components (Piqué and Chrisey, 2001).

Traditionally, Tape Casting (TC) is used for fabrication of integrated ceramic components based on co-firing flat sheets of green material (King et al., 1999). In the traditional tape casting process uniform thin sheets of films of materials such as ceramics, metals, or polymers that are readily mixed in a liquid suspension are used to build electronic components (Joe Lopes et al., 2012). This TC method works well for basic parts such as multilayer capacitors that contain only a single active ceramic. However, this technique has limitations for fabrication of multifunctional components with complex configurations (Piqué and Chrisey, 2001). 
To overcome this limitation, our group has developed a hybrid Direct-Write (DW) 3D printing technique. The DW approach allows the fabrication of 3D structures without using masks and is cost-effective for small batch manufacturing. DW technique is capable of depositing a variety of materials over different substrates to create multiple patterns of varying size, shape and feature resolution (Piqué and Chrisey, 2001). Different types of DW techniques such as laser particle guidance (Li et al., 2002), maple direct write (Chrisey, 2000), laser chemical vapor deposition (Wallenberger, 1995), micro pen, dippen (Piqué and Chrisey, 2001) and inkjet (Lewis and Gratson, 2004; Desai et al., 2013), have been used to build electronic devices. Functional devices such as integrated RC filters, multilayer voltage transformers, 555 timer circuits and other passive components were fabricated using DW techniques (Ahn et al., 2011; Aijazi, 2014; Macdonald et al., 2014).

The goal of this research is to explore the fabrication of multi-material, multi-layer hybrid integrated electronic components with higher design and material flexibility. Each of the electronic components are modeled in 3D Computer-Aided Design (CAD) format and exported to generate a tool path for the microextrusion robot. The components were built layerby-layer using conductive slurries that were embedded at different depths and orientations. The DW equipment consisted of a 4-axis robot that uses a micro-extrusion nozzle for depositing slurries on the substrate. Further, a laser beam was projected on the conductive traces after deposition of each individual layer to cure the material and avoid shrinkage between the successive layers (Lü et al., 2001; Tian et al., 2009). With this technique an electronic device with multiple properties such as insulating, semi-conducting and conducting properties can be built in a single set up. The proposed 3D manufacturing represents a paradigm shift in traditional PCB manufacturing of electronic components.

This research presents a novel additive manufacturing methodology to fabricate functional prototypes by integrating three different systems, namely micro extrusion, jetting and laser system.

\section{Materials and Methods}

The hybrid additive manufacturing technique consists of a micro extrusion robot, pico jet unit and fiber optic laser systems as shown in Fig. 1. Ultimaker ${ }^{\mathrm{TM}} 3 \mathrm{D}$ printer software was used to transfer CAD model data to the micro-extrusion robot for deposition of layers on substrate. Each layer can be fired individually by using laser after the deposition to avoid shrinkage between the layers on the substrate. Different slurry compositions can be used at different layers to build an electronic component with multiple properties. The Nordson EFD JR2200 series multi-axis robot was used for deposition of the layers. The robot has an ability to dispense lines, dots and arcs with a maximum speed of 500 millimeters (mm) per second on substrate.

PELCO $^{\circledR}$ high performance silver and nickle paste, PELCO $^{\circledR}$ conductive nickel paint, PELCO ${ }^{\circledR}$ conductive graphite and PELCO $^{\circledR}$ high temperature carbon paste was obtained from TED PELLA, Inc. Pyro-Putty 2400 and petrolatum was obtained from AREMCO and EFD Nordson, respectively. By adding solvents such as water, the viscosity of the slurry pastes was varied.

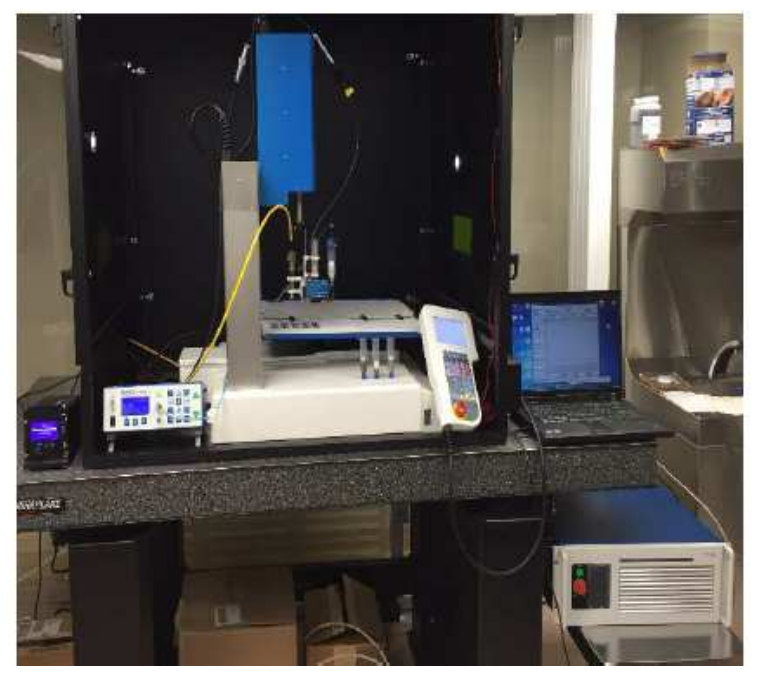

Fig. 1. Hybrid additive manufacturing equipment set up

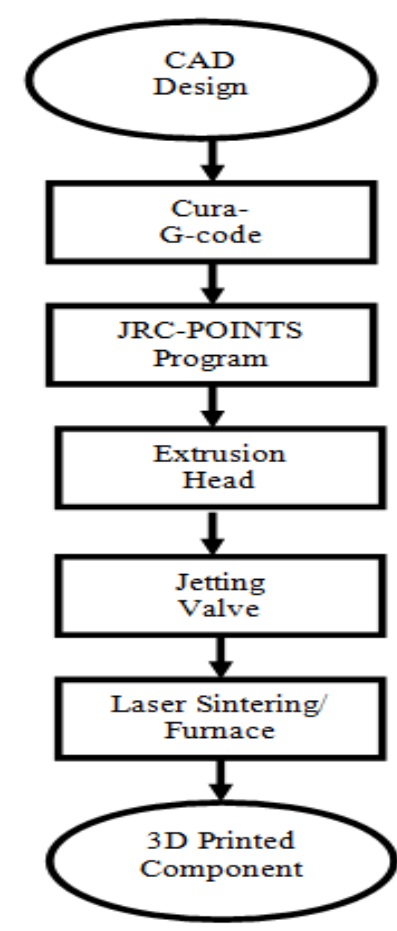

Fig. 2. Steps in the hybrid additive manufacturing process 


\section{Software}

Figure 2 shows the steps involved in the hybrid additive manufacturing process. A 3D model of the electronic device was designed in CAD. Cura ${ }^{\mathrm{TM}}$ is a software developed by UltimakerTM that can process a 3D model into a printable file. G-code of the 3D model was generated using $\mathrm{Cura}^{\mathrm{TM}}$. $\mathrm{Cura}^{\mathrm{TM}}$ incorporates all programming parameters to create a $3 \mathrm{D}$ file and has the ability to slice the model in layers.

The 3D model of the component with internal structures was designed in CAD. The model was saved as a part file and then converted to "STL" file using SolidWorks software. Cura ${ }^{\mathrm{TM}}$ can process a "STL" file of 3D model into a printable file. The CAD model was loaded into the $\mathrm{Cura}^{\mathrm{TM}}$ to generate $\mathrm{G}$-code for the model. Further, a program was created in the JR CPOINTS dispensing software. This program was exported to the multi-axis dispensing robot with a flexible interface RS-232C communication port for deposition of slurries on the substrate. The slurry compositions were deposited layer-by-layer to build a physical model of the CAD design.

\section{Hardware}

A fixture was designed to accommodate the micro extrusion head, PICO jet unit and laser head. The deposition systems employed different types of syringe barrels and valve systems. Based on the tool path pattern of the CAD model the robot maneuvers XYZ stages to deposited materials on the substrate. A micropen unit was utilized to deposit high viscosity slurries with high resolution. The picojet system which includes the PICO valve and DCON driver was used for dispensing medium viscosity fluids. The deposited materials were Laser Sintered (LS) to obtain net shaped electronic traces. The laser power and spot size were varied based on the thickness and dimensions of the traces to be sintered.

\section{Results and Discussion}

A novel direct write (DW) 3D printing technique was developed for the deposition of complex patterns using a multi-axis robot. The extruded slurry was deposited on glass and Kapton substrates. Different material compositions were utilized. The slurry pastes were loaded into the micropen (10 cc syringe barrel). The print accuracy, electrical properties and the deposition homogeneity was investigated. The print accuracy and deposition homogeneity was studied using an optical microscope (Olympus BX51). The electrical properties of the samples were measured by HP 34401A multimeter to validate the material properties and trace deposition. The conductance of the deposited samples was measured for the entire length of the deposited trace. All the deposited traces were sintered in a microwave furnace. Table 1 shows the sintering conditions such as curing temperature and time for different materials.

Table 1. Sintering conditions for different materials

\begin{tabular}{lll}
\hline Serial number & Material type & Curing temperature and time \\
\hline 1 & Carbon paste & $93^{\circ} \mathrm{C}$ for $2 \mathrm{~h}$ and $260^{\circ} \mathrm{C}$ for another $2 \mathrm{~h}$ \\
2 & Nickel paste & $93^{\circ} \mathrm{C}$ for $2 \mathrm{~h}$ \\
3 & Silver paste & $93^{\circ} \mathrm{C}$ for $2 \mathrm{~h}$ \\
4 & Nickel paint & $93^{\circ} \mathrm{C}$ for $2 \mathrm{~h}$ \\
5 & Graphite paint & $65^{\circ} \mathrm{C}$ for $30 \mathrm{~min}$ \\
\hline
\end{tabular}
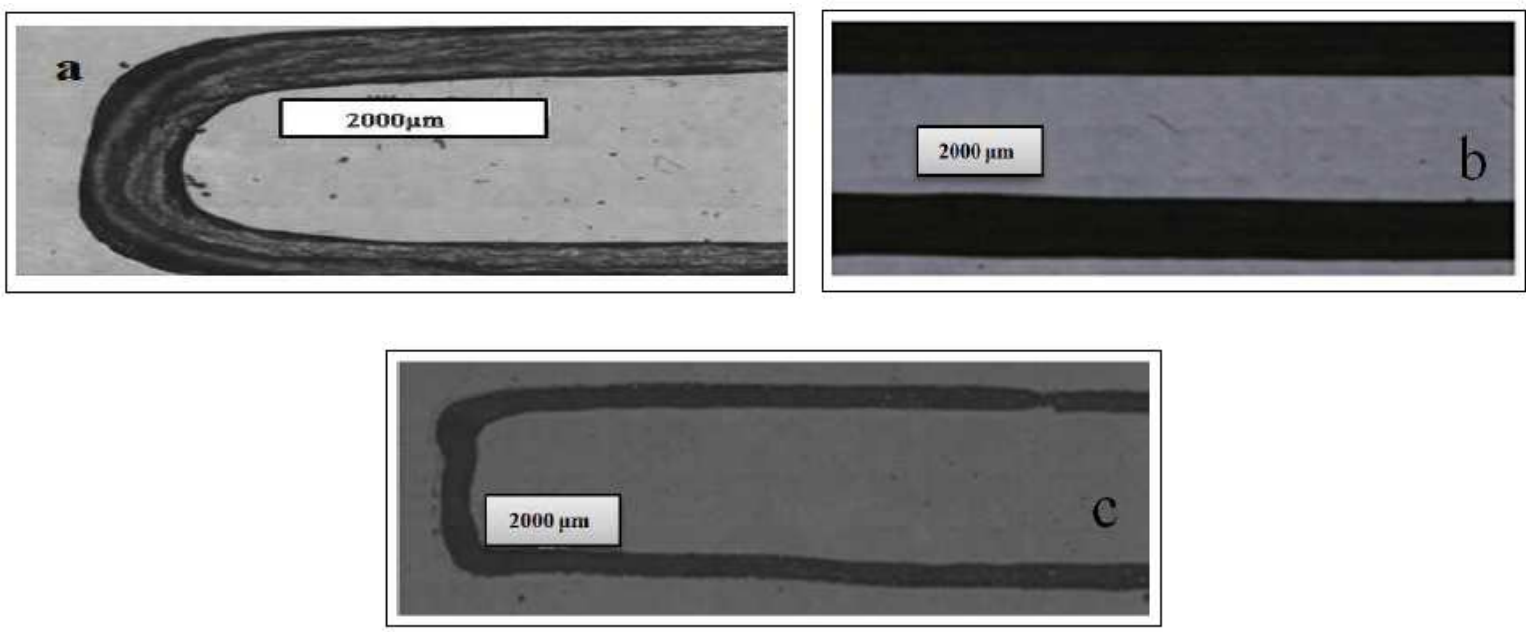

Fig. 3. Micrographs showing precise placement of (a) silver, (b) nickel and (c) carbon pastes 


\section{Print Accuracy and Deposition Homogeneity}

Precise placement of the micro-extruded slurry pastes was demonstrated as shown in Fig. 3a-c. The microscope images of the samples illustrate that the slurry pastes were micro extruded with precision on the glass slide. Figure 3a shows the fine deposition of silver paste on the glass slide. Similarly, consistent depositions of nickel and carbon pastes were observed on the glass slides as shown in Fig. 3b and 3c.

\section{Extrusion of Slurry Pastes}

Different slurry materials which include carbon, nickel and silver were loaded into $10 \mathrm{cc}$ syringe barrels, respectively. Slurry pastes were deposited on the substrate as shown in Fig. 46 and 8 by varying the microextrusion process parameters. Table 2-4 show the deposition parameters for carbon, nickel and silver slurries, respectively. Figure 5, 7 and 9 show the increase in the conductance values of the traces with an increase in their respective cross-section areas.

The results indicate that the conductance of the samples depend on parameters such as extrusion pressure, deposition line speed and material type. The extrusion pressure was dependent on the viscosity of the slurry material. Some slurries (silver) had agglomerates formed, while others (carbon) had air bubbles during deposition. The deposition speed was varied to attain different thicknesses and widths of the traces.

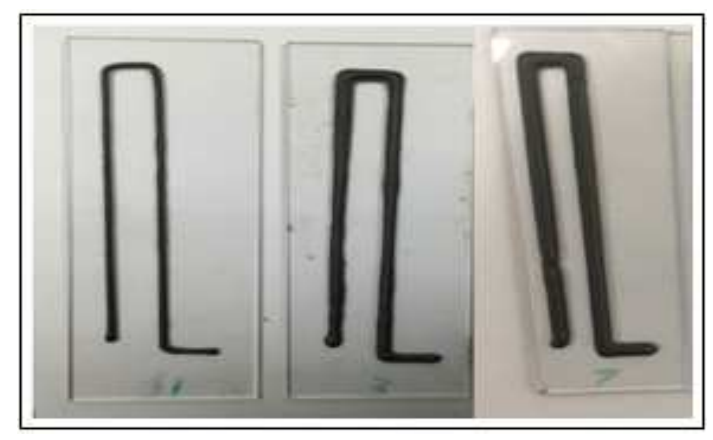

Fig. 4. Microextruded carbon samples

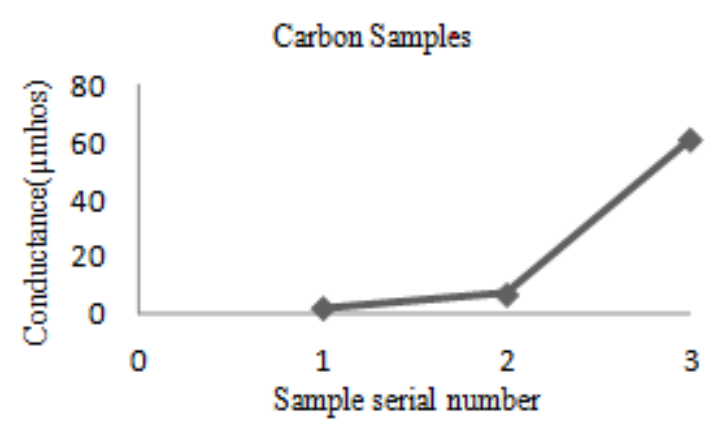

Fig. 5. Conductance of carbon slurry samples

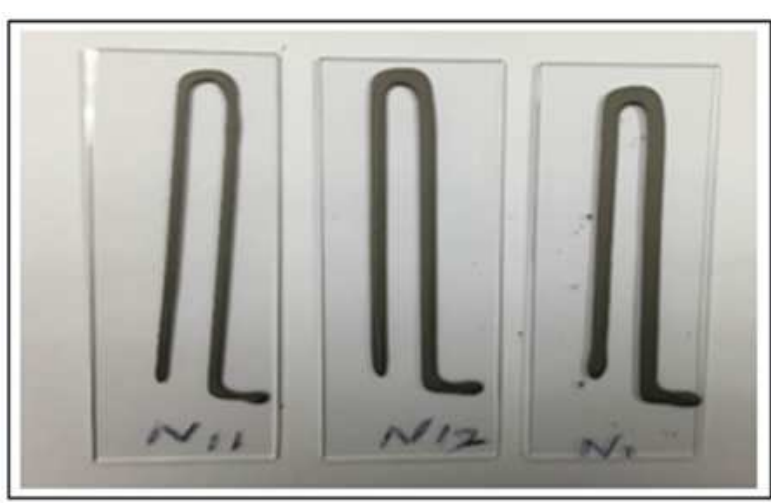

Fig. 6. Microextruded nickel samples

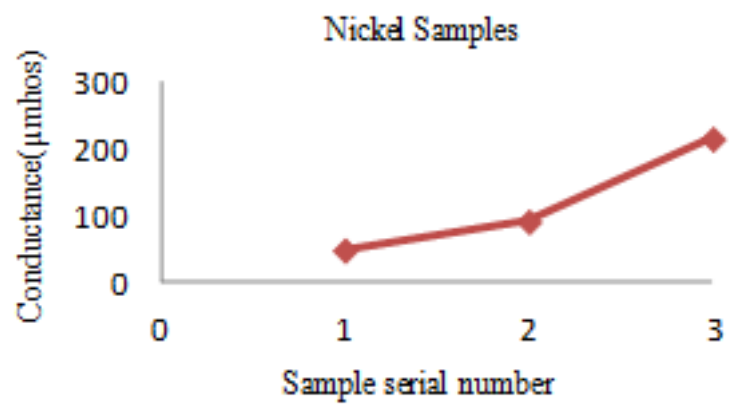

Fig. 7. Conductance of nickel slurry samples

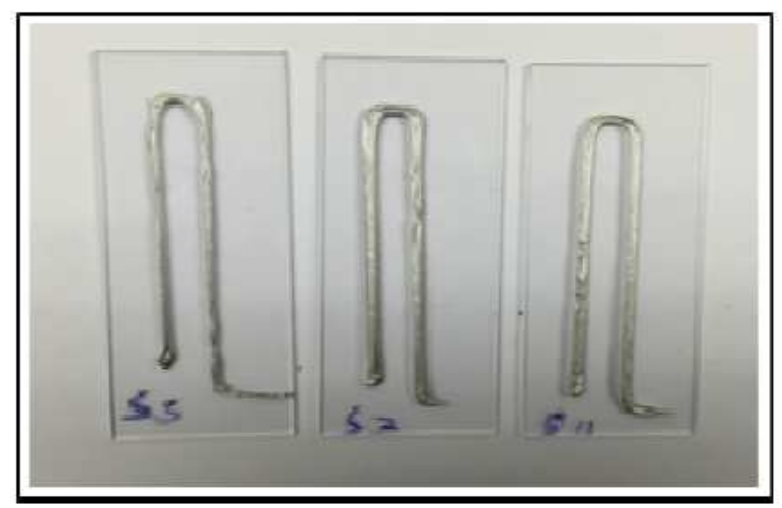

Fig. 8. Microextruded silver samples

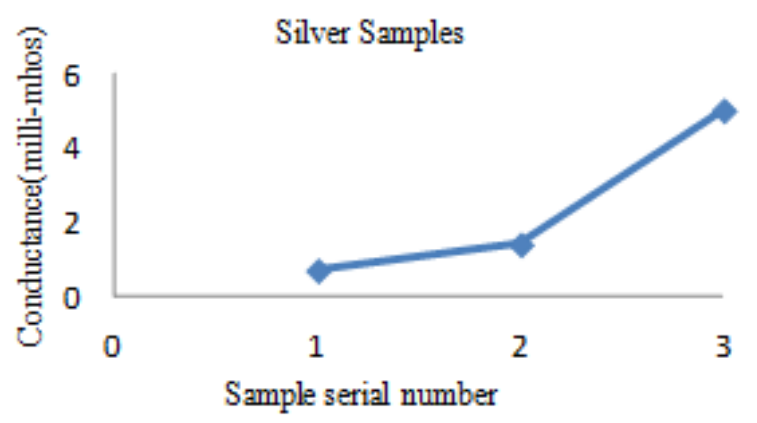

Fig. 9. Conductance of silver slurry samples 
Santosh Kumar Parupelli and Salil Desai / American Journal of Engineering and Applied Sciences 2017, 10 (1): 264.271 DOI: 10.3844/ajeassp.2017.264.271

Table 2. Process parameters for carbon slurry samples

\begin{tabular}{llcl}
\hline $\begin{array}{l}\text { Sample serial } \\
\text { number }\end{array}$ & $\begin{array}{l}\text { Deposition } \\
\text { speed }(\mathrm{mm} / \mathrm{sec})\end{array}$ & $\begin{array}{l}\text { Extrusion } \\
\text { Pressure }(\mathrm{psi})\end{array}$ & \multicolumn{1}{l}{$\begin{array}{l}\text { Cross-section } \\
\text { area }(\mathrm{square} \text { mm })\end{array}$} \\
\hline 1(Sample 11) & 20 & 10 & 0.785 \\
2(Sample 3) & 10 & 8 & 1.766 \\
3(Sample 7) & 10 & 20 & 7.95 \\
\hline
\end{tabular}

Table 3. Process parameters for nickel slurry samples

\begin{tabular}{|c|c|c|c|c|}
\hline $\begin{array}{l}\text { Sample Serial } \\
\text { number }\end{array}$ & $\begin{array}{l}\text { Deposition } \\
\text { speed }(\mathrm{mm} / \mathrm{sec})\end{array}$ & $\begin{array}{l}\text { Extrusion } \\
\text { Pressure (psi) }\end{array}$ & $\begin{array}{l}\text { Cross-section } \\
\text { area (square mm) }\end{array}$ & $\begin{array}{l}\text { Conductance } \\
\text { ( } \mu \text { mhos })\end{array}$ \\
\hline 1(Sample 11) & 20 & 8 & 3.14 & 48.86 \\
\hline 2(Sample 12) & 25 & 15 & 4.90 & 91.84 \\
\hline 3(Sample 7) & 20 & 15 & 7.06 & 215.66 \\
\hline
\end{tabular}

Table 4. Process parameters for silver slurry samples

\begin{tabular}{llll}
\hline $\begin{array}{l}\text { Sample } \\
\text { Serial number }\end{array}$ & $\begin{array}{l}\text { Deposition } \\
\text { speed }(\mathrm{mm} / \mathrm{sec})\end{array}$ & $\begin{array}{l}\text { Extrusion } \\
\text { Pressure }(\mathrm{psi})\end{array}$ & $\begin{array}{l}\text { Cross-section } \\
\text { area (square mm) }\end{array}$ \\
\hline 1(Sample 5) & 30 & 25 & 0.94 \\
2(Sample 7) & 25 & 25 & 1.76 \\
3(Sample 11) & 20 & 30 & 3.14 \\
\hline
\end{tabular}

Table 5. Process parameters for nickel paint samples

\begin{tabular}{lllll}
\hline $\begin{array}{l}\text { Sample } \\
\text { Serial number }\end{array}$ & $\begin{array}{l}\text { Pulse time } \\
\text { and Cycle time }\end{array}$ & $\begin{array}{l}\text { Deposition speed }(\mathrm{mm} / \mathrm{sec}) \\
\text { and Extrusion Pressure }(\mathrm{psi})\end{array}$ & $\begin{array}{l}\text { Cross-section } \\
\text { area (square mm) }\end{array}$ & $\begin{array}{l}\text { Conductance } \\
(\mathrm{millimhos})\end{array}$ \\
\hline 1(Sample 7) & 1 and 50 & 10 and 60 & 0.31 & 0.010 \\
2(Sample 9) & 1 and 30 & 10 and 55 & 0.39 & 0.032 \\
3(Sample 17) & 1 and 20 & 10 and 50 & 0.50 & 0.191 \\
\hline
\end{tabular}

Table 6. Process parameters for graphite paint samples

\begin{tabular}{lllll}
\hline $\begin{array}{l}\text { Sample } \\
\text { Serial number }\end{array}$ & $\begin{array}{l}\text { Pulse time } \\
\text { and Cycle time }\end{array}$ & $\begin{array}{l}\text { Deposition speed }(\mathrm{mm} / \mathrm{sec}) \\
\text { and Extrusion Pressure }(\mathrm{psi})\end{array}$ & $\begin{array}{l}\text { Cross-section } \\
\text { area (square mm) }\end{array}$ & $\begin{array}{l}\text { Conductance } \\
(\mu \mathrm{mhos})\end{array}$ \\
\hline 1(Sample 12) & 1 and 100 & 10 and 20 & 0.66 & 0.004 \\
2(Sample 9) & 1 and 50 & 10 and 10 & 1.57 & 0.017 \\
3(Sample 1) & 1 and 10 & 10 and 15 & 1.89 & 0.032 \\
\hline
\end{tabular}

In all the cases, the conductance of the samples increased with an increase in the cross-section area of the trace. Silver samples had the highest conductance values followed by nickel and carbon samples, respectively (silver $>$ nickel $>$ carbon).

\section{Jetting of Medium Viscous Colloids}

Colloidal paints which include nickel paint and conductive graphite paint were loaded into $10 \mathrm{cc}$ syringe barrels, respectively. The PICO jet unit was used to deposit the colloidal paints on the substrate as shown in Fig. 10 and 12. Table 5 and 6 show the deposition parameters for nickel and graphite paint using the PICO jet unit, respectively. The PICO jet unit operates by varying the ratio between pulse and cycle time. The pulse time is when the picojet valve remains open, whereas the cycle time is the total time which includes open and closed valve timings.
The findings indicated that the conductance values of the jetting samples were in the increasing order, starting with nickel paint followed by graphite paint (nickel paint< $<$ graphite). It was also observed that the electrical properties such as conductance depends on jetting parameters such as pulse time, cycle time, extrusion pressure and deposition line speed. Figure 11 and 13 show the increase in the conductance values of the traces based on process parameters discussed in Table 5 and 6.

\section{Deposition of Multiple Patterns}

Our team demonstrated the deposition of different pattern designs in a variety of materials as shown in Fig. 14. These patterns represent the shapes of traces used in different electronic components. The materials used included carbon paste, nickel paint, silver paste and petrolatum. Silver paste was deposited on the 
flexible Kapton substrate (Fig, 14a). A combination of silver paste and nickel paint were deposited in sequence as shown in Fig. 14b. Figure $14 \mathrm{c}$ and $14 \mathrm{~d}$ show the deposition of carbon paste and petrolatum, respectively. Table 7 shows the process parameters for deposition of different materials. Figure 15 shows the conductance values for multi-material samples. For sample 2, the microextrusion was used for extruding the silver paste followed by the jetting of the nickel paint using the PICO jet unit. The silver trace was discontinuous and showed no conductivity. However, nickel paint was jetted on top of the entire silver trace to make it conductive. Thus, microextruded slurry traces can be infiltrated in situ with other conductive fluids to change the electrical properties of the resultant trace. The trace with petrolatum material did not show any conductance as it is an insulating material. The results illustrate that multiple patterns with different materials can be deposited on the substrate in a preset manner.

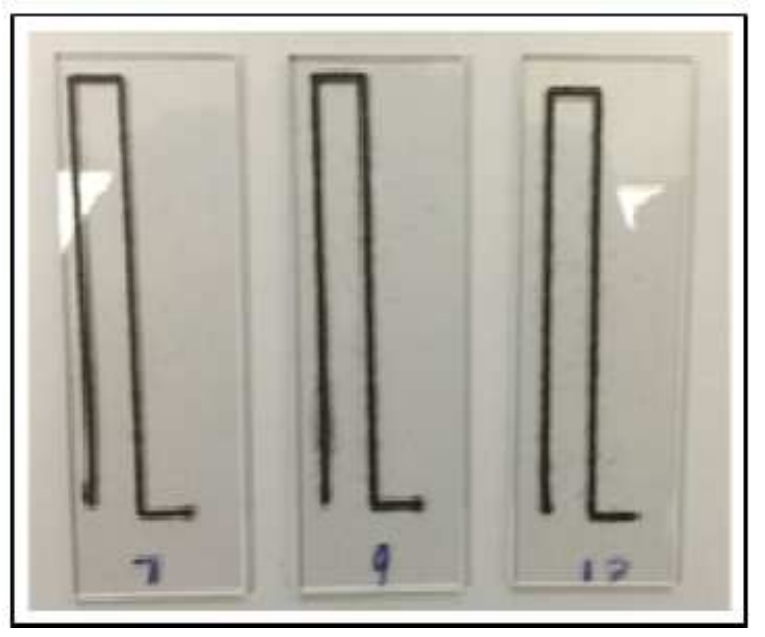

Fig. 10. Nickel paint samples

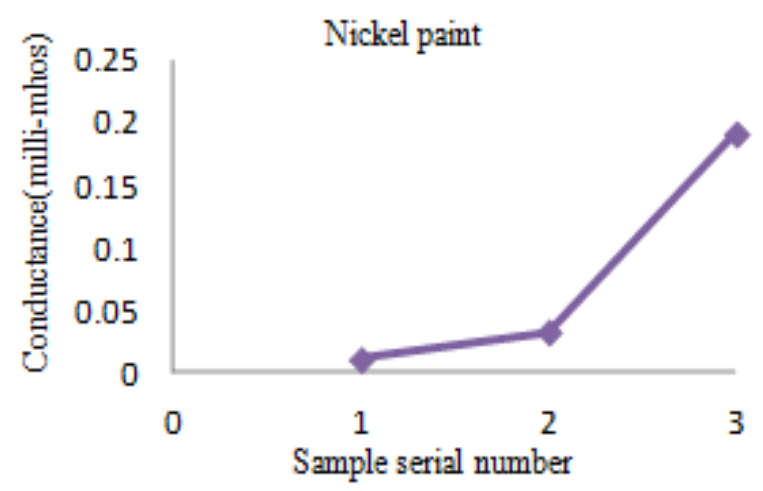

Fig. 11. Conductance of nickel paint samples

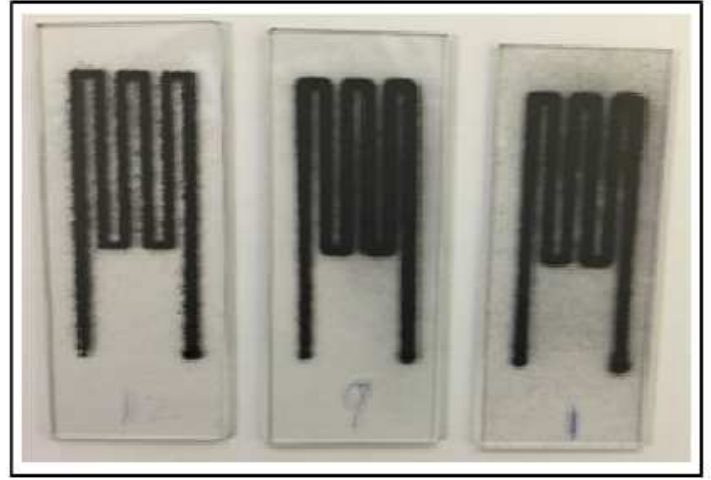

Fig. 12. Graphite paint samples

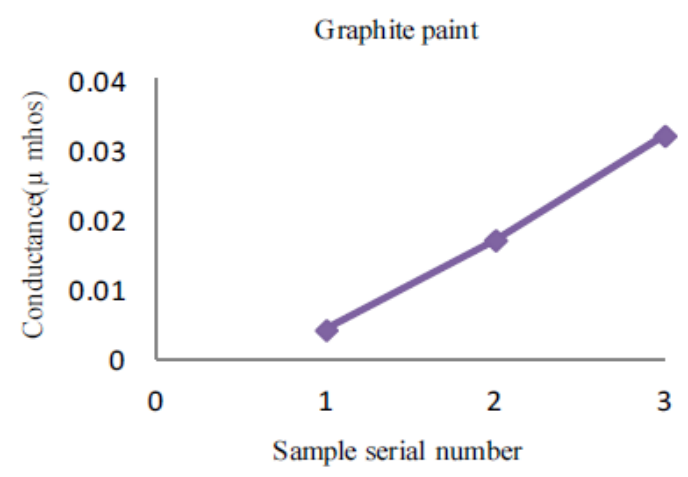

Fig. 13. Conductance of graphite paint samples

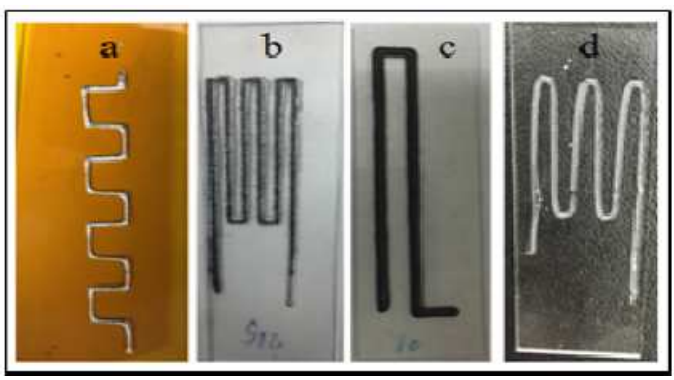

Fig. 14. Multi-material traces printed using the hybrid additive manufacturing process

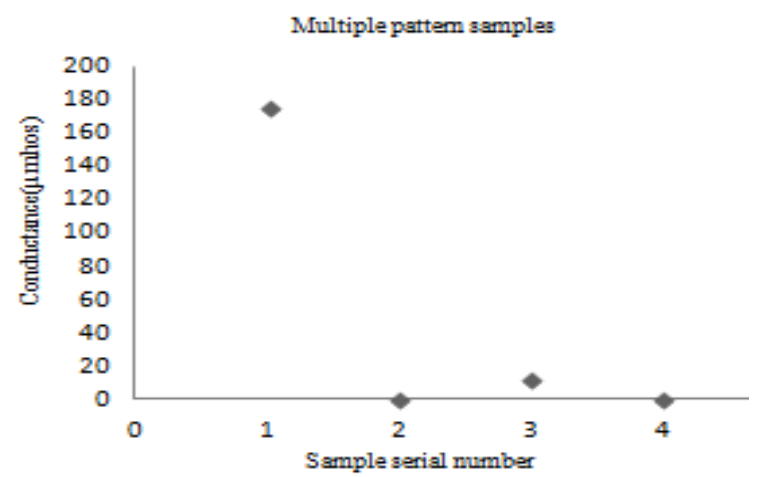

Fig. 15. Plot of multiple pattern samples conductance values 


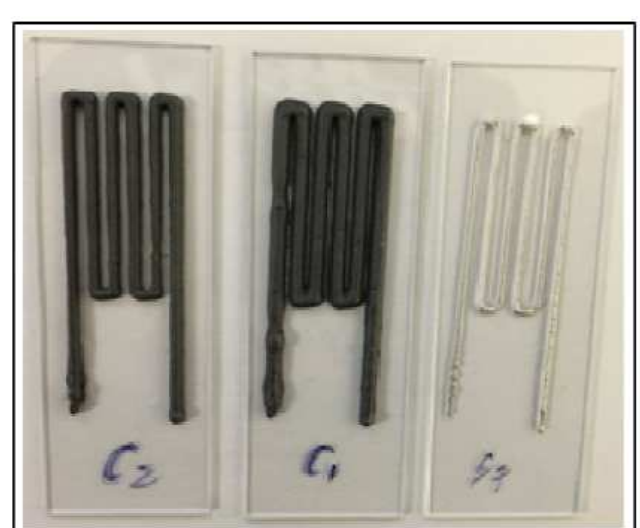

Fig. 16. Laser cured samples

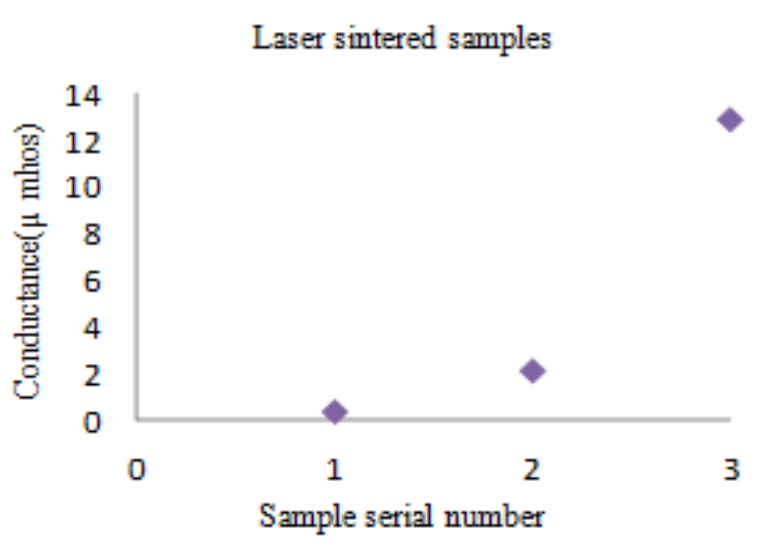

Fig. 17. Conductance of laser cured samples

Table 7. Process parameters for multiple pattern samples

\begin{tabular}{lllll}
\hline $\begin{array}{l}\text { Sample } \\
\text { Serial number }\end{array}$ & $\begin{array}{l}\text { Pulse time } \\
\text { and cycle time }\end{array}$ & $\begin{array}{l}\text { Deposition speed }(\mathrm{mm} / \mathrm{sec}) \\
\text { and ExtrusionPressure }(\mathrm{psi})\end{array}$ & $\begin{array}{l}\text { Cross-section } \\
\text { area (square } \mathrm{mm})\end{array}$ & $\begin{array}{l}\text { Conductance } \\
(\mu \mathrm{mhos})\end{array}$ \\
\hline $1(\mathrm{Silver})$ & - & 10 and 35 & 0.39 & 176.56 \\
$2(\mathrm{Ag}+\mathrm{Ni})$ & 1 and 50 & 10 and 8 & 0.31 & 0.041 \\
$3($ Carbon) & - & 15 and 20 & 1.57 & 12.21 \\
4-Petrolatum & - & 15 and 25 & - & - \\
\hline
\end{tabular}

Table 8. Process parameters for laser cured samples

\begin{tabular}{llllc}
\hline $\begin{array}{l}\text { Sample } \\
\text { Serial number }\end{array}$ & $\begin{array}{l}\text { Laser beam spot size }(\mathrm{mm}) \\
\text { and laser power }(\text { watt })\end{array}$ & $\begin{array}{l}\text { Deposition speed }(\mathrm{mm} / \mathrm{sec}) \\
\text { and ExtrusionPressure }(\mathrm{psi})\end{array}$ & $\begin{array}{l}\text { Cross-section } \\
\text { area (square mm) }\end{array}$ & $\begin{array}{l}\text { Conductance } \\
(\mu \mathrm{mhos})\end{array}$ \\
\hline 1(Sample C2) & 2 and 24 & 15 and 8 & 0.56 & 0.44 \\
2(Sample C1) & 2 and 21, 24 & 10 and 10 & 1.27 & 2.19 \\
3 (Sample S7) & 2 and 24 & 15 and 35 & 0.31 & 12.94 \\
\hline
\end{tabular}

\section{Laser Curing}

Laser curing of carbon and silver paste was performed using a fiber-optic YAG laser. Figure 16 shows laser cured samples of the deposited materials. The laser power intensity and spot size were important parameters in the sintering process. Both of these parameters were varied to observe their effect on the conductance of the traces. We have demonstrated that in situ laser curing has shown to be an energy efficient method for sintering electrical traces. Moreover, laser curing was performed for a short duration (1-2 min) with multiple passes to fully sinter the sample. The targeted sintering of the samples can enable variable curing ability for multiple materials within the trace. Table 8 shows the deposition parameters for the laser cured samples. The laser spot size was held constant at $2 \mathrm{~mm}$ and the laser power was modulated for each sample. Figure 17 shows the increase in the conductance values of the carbon traces with an increase in the cross-section area. Further, the trace printed with silver had the highest conductance value. These results demonstrate the in situ sintering capability of the hybrid additive manufacturing process for different materials.

\section{Conclusion}

This paper presents a hybrid additive manufacturing technology which integrates microextrusion, picojet and laser systems. Materials in the form of slurries and colloidal paints were used for the deposition on both rigid and flexible substrates. Several process parameters were manipulated to deposit precise traces of carbon, nickel and silver slurries. Similarly, colloids of nickel and graphite were jetted on the substrate to evaluate their electrical properties. Precision deposition of patterns was observed for the slurries on glass and Kapton substrates. The electrical properties and the deposition accuracy of the samples were investigated using a multimeter and optical microscope, respectively. CAD software tools were integrated with the robot hardware for fine deposition of the traces. The traces were cured using both microwave furnace and fiber-optic laser system. Laser sintering permitted controlling the local microstructure of the samples and thereby impacting the electrical properties. Silver traces had the highest conductance values followed by nickel and carbon. Multi-material traces were deposited by microextruding silver paste and picojetting nickel 
paint on top of it. This research forms the basis to manipulate material type and process parameters to build functional electronic devices. With this new technique, electronic components such as capacitors, inductors, antennas, transistor and strain gauge with complex patterns and multiple materials can be fabricated in a single set up.

\section{Funding Information}

The authors gratefully acknowledge the support of the National Science Foundation (NSF) for funding the project through Combinatorial Additive Manufacturing Approach for Fabricating Nano/Micro 3D Structures (grant No. NSF CMMI: Award 1435649).

\section{Author's Contributions}

Mr. Parupelli and Dr. Desai performed laboratory work and conducted data analysis of the research. All authors contributed to the writing of the manuscript.

\section{Ethics}

The authors declare that there are no ethical issues that could arise after the publication of this study.

\section{References}

Ahn, B.Y., S.B. Walker, S.C. Slimmer, A. Russo and A. Gupta et al., 2011. Planar and three-dimensional printing of conductive inks. J. Visualized Exp., 58: e3189-e3189. DOI: $10.3791 / 3189$

Aijazi, A.T., 2014. Printing functional electronic circuits and components. Published dissertation in partial fulfillment of the requirements for the degree of Doctor of Philosophy, Western Michigan University, Kalamazoo Michigan, USA.

Chrisey, D.B., 2000. The power of direct writing. Science, 289: 879-881.

DOI: $10.1126 /$ science. 289.5481 .879

Desai, S., M. Craps and Taye Esho, 2013. Direct writing of nanomaterials for flexible Thin-Film Transistors (fTFTs). Int. J. Adv. Manufact. Technol., 64: 537-543. DOI: $10.1007 / \mathrm{s} 00170-012-4425-4$

Espalin, D., D.W. Muse, E. MacDonald and R.B. Wicker, 2014. 3D Printing multifunctionality: Structures with electronics. Int. J. Adv. Manufact. Technol., 72: 963-978. DOI: 10.1007/s00170-014-5717-7

Gomes, E., 2012. Printed circuit board.

Joe Lopes, A., E. MacDonald and R.B. Wicker, 2012. Integrating stereolithography and direct print technologies for 3D structural electronics fabrication. Rapid Prototyp. J., 18: 129-143.

DOI: $10.1108 / 13552541211212113$
King, B., D. Dimos, P. Yang and S.L. Morissette, 1999. Direct-write fabrication of integrated, multilayer ceramic components. J. Electroceram., 3: 173-178. DOI: $10.1023 / \mathrm{A}: 1009999227894$

Lewis, J.A. and G.M. Gratson, 2004. Direct writing in three dimensions. Mater. Today, 7: 32-39. DOI: $10.1016 / \mathrm{S} 1369-7021(04) 00344-\mathrm{X}$

Li, X., H. Choi and Y. Yang, 2002. Laser-based meso/micro rapid manufacturing system. Solid Freeform Fabrication Proc.

Lim, S.R. and J.M. Schoenung, 2010. Human health and ecological toxicity potentials due to heavy metal content in waste electronic devices with flat panel displays. J. Hazardous Mater., 177: 251-259. DOI: 10.1016/j.jhazmat.2009.12.025

Lü, L., J.Y.H. Fuh and Y.S. Wong, 2001. Laser Sintering of Ceramics. In: Laser-Induced Materials and Processes for Rapid Prototyping, Lü, L., J.Y.H. Fuh and Y.S. Wong (Eds.), Springer, pp: 187-199.

Macdonald, E., R. Salas, D. Espalin, M. Perez and E. Aguilera et al., 2014. 3D printing for the rapid prototyping of structural electronics. IEEE Access, 2: 234-242. DOI: 10.1109/ACCESS.2014.2311810

Palm, P., J. Moisala, A. Kivikero, R. Tuominen and A. Iihola, 2005. Embedding active components inside Printed Circuit Board (PCB) - a solution for miniaturization of electronics. Proceedings of the International Symposium on Advanced Packaging Materials: Processes, Properties and Interfaces, Mar. 16-18, IEEE Xplore Press, pp: 1-4.

DOI: 10.1109/ISAPM.2005.1432034

Park, S., M. Vosguerichian and Z. Bao, 2013. A review of fabrication and applications of carbon nanotube film-based flexible electronics. Nanoscale, 5: 1727-1752. DOI: 10.1039/C3NR33560G

Piqué, A. and D.B. Chrisey, 2001. Direct-Write Technologies for Rapid Prototyping Applications: Sensors, Electronics and Integrated Power Sources. 1st Edn., Academic Press, San Diego, ISBN-10: 0080504647, pp: 726.

Rashid, M.H., 2010. Power Electronics Handbook: Devices, Circuits and Applications. 2nd Edn., Academic Press, ISBN-10: 0080467652, pp: 1192.

Tian, X., J. Günster, J. Melcher and J.G. Heinrich, 2009. Process parameters analysis of direct laser sintering and post treatment of porcelain components using Taguchi's method. J. Eur. Ceramic Society, 29: 1903-1915.

DOI: $10.1016 /$ j.jeurceramsoc.2008.12.002

Wallenberger, F.T., 1995. Rapid prototyping directly from the vapor phase. Science, 267: 1274-1275. DOI: $10.1126 /$ science.267.5202.1274 